\title{
Cyclosporin A in psoriatic arthritis: an open study
}

\author{
K Steinsson, I Jónsdóttir, H Valdimarsson
}

\begin{abstract}
Eight patients with psoriatic arthritis entered an open study to determine the efficacy of oral cyclosporin A for their treatment. The starting dose was $3.5 \mathrm{mg} / \mathrm{kg}$ daily. Findings after the first six months are reported. One patient withdrew from the study after five months because of tremors, general malaise, and lack of improvement. Seven patients continued through the study, and marked improvement was found after two months in all clinical indices. The skin lesions improved in a parallel fashion. The cyclosporin A dose had to be reduced temporarily by $25 \%$ in three patients because of an increase in serum creatinine of more than $50 \%$. A rise in diastolic blood pressure in three patients responded to treatment. The study suggests that cyclosporin A effectively treats arthritic manifestations of psoriasis as well as psoriatic skin lesions.
\end{abstract}

There is now strong circumstantial evidence that psoriatic skin lesions occur when CD4+ T lymphocytes infiltrate the epidermis of genetically susceptible subjects. ${ }^{1-3}$ The genetic factors predisposing to the psoriatic epidermal response have not been characterised, but are likely to entail abnormal homeostatic control of keratinocyte growth, including hyperproliferative response to products of activated $\mathrm{T}$ lymphocytes. $^{4}$

It has now been conclusively shown that cyclosporin $A$ is effective in clearing psoriatic skin lesions. ${ }^{5-8}$ Because similar pathogenic mechanisms are likely to function in the skin and joints in psoriasis it was decided to test the effect of this drug on patients with severe psoriatic arthritis. Systematic evaluation of the effect of cyclosporin A on psoriatic arthritis has not been reported, but improvement of arthritis has been noted in individual patients during cyclosporin A treatment for skin lesions (L Fry, unpublished data).

We now present the results of the first six months of an open study on the effectiveness and safety of cyclosporin $A$ in psoriatic arthritis.

\section{Patients and methods}

STUDY DESIGN

The study was divided into three phases of six months each, and its aim was to evaluate the feasibility of a controlled multicentre trial. The first phase was designed to determine whether a low dose of cyclosporin $A$ is effective for psoriatic arthritis. In phase 2 it is intended to determine the minimal effective maintenance dose in patients who have improved sufficiently during phase 1 . Finally, in phase 3 it is planned to discontinue the treatment and compare the duration of the cyclosporin $A$ induced improvement both in skin and joints.

\section{CYCLOSPORIN A DOSAGE}

The initial dose of cyclosporin A was $3.5 \mathrm{mg} / \mathrm{kg}$ daily and the intention was to increase this to $5.0 \mathrm{mg} / \mathrm{kg}$ daily after three months if there was less than $50 \%$ improvement in the joint count according to the American Rheumatism Association (ARA). The dose of cyclosporin A was reduced by $25 \%$ if the serum creatinine concentrations increased by more than $50 \%$ over the baseline value for each patient or above $130 \mu \mathrm{mol} / \mathrm{l}$. The dose was similarly reduced by $25 \%$ if total bilirubin or liver transaminases increased by more than $100 \%$ over baseline or reached more than three times the upper limit of normal.

The cyclosporin A dose was not to be adjusted according to blood concentrations of the drug unless trough whole blood concentrations above $500 \mu \mathrm{g} / \mathrm{l}$ were found on two consecutive measurements.

\section{PATIENTS}

Eight patients (four male, four female; mean age 46 years, range 22-56) were entered into the study. All were unresponsive to conventional treatment and seven had previously not improved with methotrexate treatment. Informed consent was obtained from the patients.

Inclusion criteria were as follows : (a) seronegative polyarthritis (Rose-Waaler and enzyme linked immunosorbent assay (ELISA) isotypes) and active psoriatic lesions affecting at least $20 \%$ of the total body surface and not responding to local treatment; (b) psoriatic arthritis, regardless of the extent of skin disease, if the arthritis was not adequately controlled with non-steroidal anti-inflammatory drugs, and cytotoxic agents were the alternative

Excluded from the study were patients with one or more of the following: Previous treatment with cyclosporin A. Treatment with psoralen and ultraviolet light, systemic steroids, sulphasalazine, methotrexate, etretinate, or other immunosuppressive agents within the last eight weeks before proposed entry into the study. Serum creatinine over $110 \mu \mathrm{mol} / \mathrm{l}$ (normal range 62-115), reduced chromium EDTA clearance, proteinuria $>0.5 \mathrm{~g} / 24$ hours, 
or cellular casts on urine analysis. Leucopenia, thrombocytopenia, or abnormal liver function tests. Hypertension (diastolic blood pressure $>95 \mathrm{mmHg}$ after five minutes in sitting position). Malignancy or history of malignancy, including skin cancer. Uncontrolled infections. Women who were pregnant, breast feeding, or not practising contraception. Impairment of cardiovascular or cerebral function. Insulin dependent diabetes, epilepsy, or malabsorption. Drug or alcohol abuse and uncooperative patients who were unlikely to comply.

\section{ASSESSMENT OF DISEASE ACTIVITY}

Each patient was examined by the same rheumatologist (KS) every two weeks for two months and monthly thereafter for possible side effects. Assessment of disease activity was made at entry and after two, three, and six months.

The following clinical variables were evaluated at each visit: (a) ARA joint count of 66 diarthrodial joints (tenderness on pressure and on passive movement, or swelling other than bony proliferation, or both) ${ }^{9} ;(b)$ overall joint tenderness, expressed as the Ritchie articular index ${ }^{10} ;(c)$ number of swollen joints; $(d)$ duration of morning stiffness in minutes; $(e)$ patient's assessment of pain graded on a $10 \mathrm{~cm}$ visual analogue scale; $(f)$ doctor's global assessment of disease activity using 5 as a starting point on a $10 \mathrm{~cm}$ scale.

When appropriate, grip strength was measured for both hands (means of three readings for each) with a standard cuff inflated to $20 \mathrm{mmHg}$.

The extent of skin disease was determined from photographs taken at entry and after three and six months. Blood pressure was measured at each visit.

\section{LABORATORY ASSESSMENTS}

The following tests were carried out at each visit: complete blood and differential count, erythrocyte sedimentation rate, serum creatinine, urine analysis, and cyclosporin A concentrations in whole blood with radioimmunoassay using polyclonal antibodies. Serum potassium, uric acid, albumin, total bilirubin, liver transaminases, alkaline phosphatase, and immunoglobulins were also measured when disease activity was assessed.
STATISTICAL ANALYSIS

Statistical analysis of the clinical variables was performed using the paired Student's $t$ test (two tailed). For each clinical variable the level of significance was set at $\mathrm{p}<0.05$.

\section{Results}

The eight patients received no other treatment for their skin or arthritic manifestations except for non-steroidal anti-inflammatory agents.

One patient discontinued cyclosporin $\mathrm{A}$ after five months because of tremors, general malaise, and poor clinical response. Eight patients were therefore evaluated after two and three months, but only seven patients after six months.

The table gives the mean values for each clinical variable, creatinine, and cyclosporin A doses, and the figure shows the changes found for individual patients in ARA joint count, Ritchie index, morning stiffness, and pain.

The other clinical variables followed a similar course. Grip strength improved markedly in four patients, two had only marginally reduced grip strength at entry, and in one patient this measurement was not possible owing to mutilation of all fingers. A significant improvement in all clinical indices was evident for the group as a whole after two months, and further progressive improvement was noted in the seven patients who remained in the study.

There was a close correlation between improvement in the arthritis and the skin lesions. Five patients had more than $20 \%$ of their skin affected (range $20-80 \%$ ) at entry. After three months' treatment these lesions had improved by $70-82 \%$ in all these patients. This improvement continued throughout the study, and the skin lesions had almost disappeared after six months. Six patients were taking nonsteroidal anti-inflammatory drugs at entrythree were able to discontinue this treatment and one could reduce the dose by half.

Of the seven patients who remained in the study, only one required the higher dose of $5 \mathrm{mg} / \mathrm{kg}$ cyclosporin A daily and one patient required only $2-3 \mathrm{mg} / \mathrm{kg}$ daily. The table shows the mean cyclosporin A dose during the six months of treatment.

ADVERSE REACTIONS

Three patients developed asymptomatic hyper-

Clinical findings at entry and during the cyclosporin A treatment. Values for the clinical variables are given as mean (SD) with the percentage change from the mean value at entry given in parentheses below

\begin{tabular}{|c|c|c|c|c|c|}
\hline Variables & $\begin{array}{l}\text { Entry } \\
(n=8)\end{array}$ & $\begin{array}{l}2 \text { Months } \\
(n=8)\end{array}$ & $\begin{array}{l}3 \text { Months } \\
(n=8)\end{array}$ & $\begin{array}{l}6 \text { Months } \\
(n=7)\end{array}$ & $\stackrel{p}{\text { Value }}$ \\
\hline ARA joint count & $28 \cdot 6(10 \cdot 8)$ & $18 \cdot 9(8 \cdot 5)$ & $\begin{array}{l}15 \cdot 9(11 \cdot 9) \\
(44)\end{array}$ & $\underset{(67)}{9 \cdot 4}(7 \cdot 2)$ & 0.0014 \\
\hline Ritchie index & $26 \cdot 3(8 \cdot 9)$ & $\begin{array}{ll}13 \cdot 6 & (7 \cdot 6) \\
(48) & \end{array}$ & $12 \cdot 3(8 \cdot 0)$ & $\begin{array}{cc}7 \cdot 4 \\
(72)\end{array}$ & 0.0009 \\
\hline No of swollen joints & $7 \cdot 3 \quad(5 \cdot 3)$ & $\begin{array}{r}3.9 \\
(46)\end{array}$ & $\begin{array}{cc}2 \cdot 8 & (2 \cdot 9) \\
(62) & \end{array}$ & $\begin{array}{c}1.4 \\
(81)\end{array} \quad(1 \cdot 3)$ & $0 \cdot 023$ \\
\hline Duration of morning stiffness (min) & $86 \cdot 3(51 \cdot 8)$ & $\begin{array}{l}33 \cdot 8(29 \cdot 7) \\
(61)\end{array}$ & $45 \cdot 0(60 \cdot 0)$ & $\begin{array}{l}17 \cdot 1(29 \cdot 2) \\
(80)\end{array}$ & 0.003 \\
\hline Patient's pain score & $5 \cdot 9(2 \cdot 2)$ & $\begin{array}{cc}2 \cdot 8 & (1 \cdot 8) \\
(52) & \end{array}$ & $\begin{array}{r}2 \cdot 5 \\
(58)\end{array}(2 \cdot 1)$ & $\begin{array}{r}2 \cdot 3 \\
(61)\end{array}(1 \cdot 2)$ & 0.019 \\
\hline Doctor's global assessment & $5 \cdot 0(0)$ & $\begin{array}{cc}3 \cdot 8 & (0.5) \\
(24) & \end{array}$ & $\begin{array}{c}2 \cdot 8 \\
(44)\end{array}(1 \cdot 0)$ & $\begin{array}{c}2 \cdot 2 \\
(56)\end{array}(1 \cdot 0)$ & 0.005 \\
\hline $\begin{array}{l}\text { Cyclosporin A dose (mg/kg) } \\
\text { Serum creatinine }(\mu \mathrm{mol} / \mathrm{l})\end{array}$ & $\begin{array}{l}3 \cdot 5(0) \\
73 \cdot 1(17 \cdot 9)\end{array}$ & $\begin{array}{r}3 \cdot 4(0 \cdot 3) \\
81 \cdot 2(22 \cdot 9)\end{array}$ & $\begin{array}{l}3 \cdot 3(0 \cdot 5) \\
79 \cdot 3(18 \cdot 6)\end{array}$ & $\begin{array}{r}3 \cdot 6(0 \cdot 6) \\
82 \cdot 8(13 \cdot 8)\end{array}$ & \\
\hline
\end{tabular}

*The $\mathrm{p}$ values were calculated for differences between findings at entry and after six months receiving cyclosporin $\mathbf{A}$. 
Changes in American Rheumatism Association (ARA) joint count, Ritchie index, morning stiffness, and pain in individual patients receiving cyclosporin A treatment.
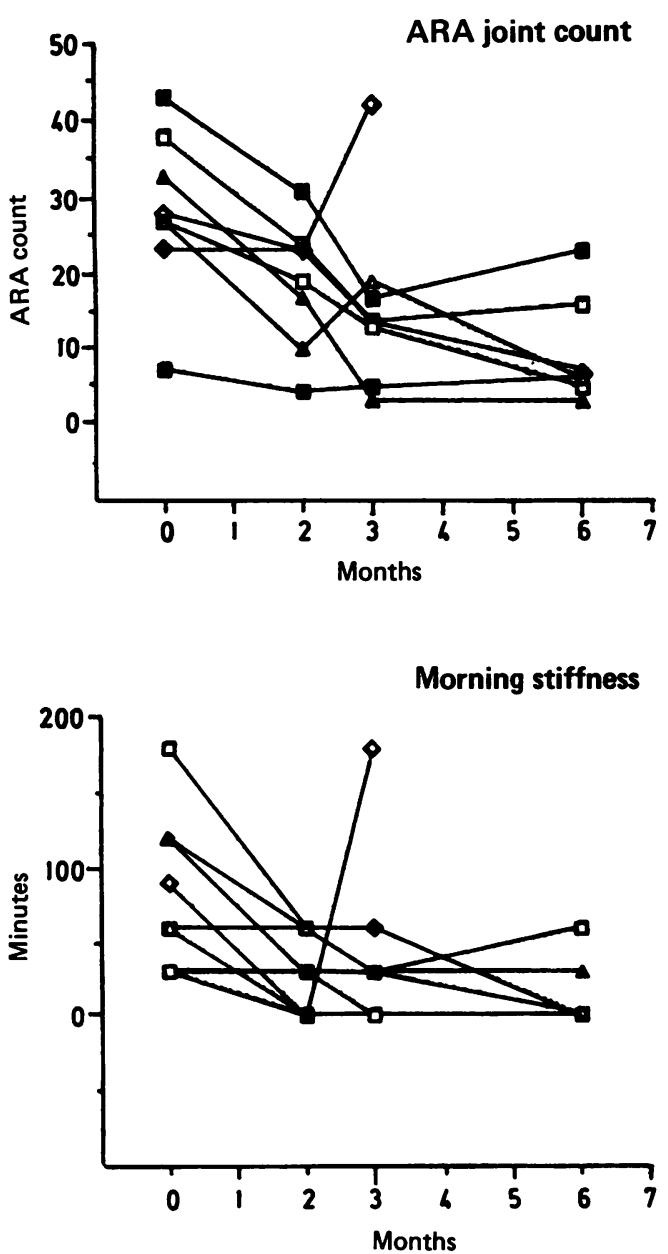

tension, but their diastolic pressure did not exceed $100 \mathrm{mmHg}$, and all responded to treatment with frusemide or calcium blocking agents.

An increase in serum creatinine by $50 \%$ above the baseline value occurred on four occasions in three patients (once in two patients and twice in one patient), and the highest serum creatinine value was $130 \mu \mathrm{mol} / \mathrm{l}$. The rise in creatinine was reversible in all instances when the cyclosporin A dose was temporarily reduced by a quarter. The table shows the mean serum creatinine values at entry and after two, three, and six months.

Mild microscopic haematuria (two to five red blood cells on one occasion) was found in one patient and mild cylindruria (one to five granular casts on several occasions) was found in two patients. There was no other evidence of kidney disease in these patients.

One patient developed mild gingival hyperplasia, which resolved with $25 \%$ reduction in the cyclosporin $A$ dose. In one patient a threefold increase in $S$-aspartate aminotransferase was noted after six months, which returned to normal with $25 \%$ reduction in the cyclosporin A dose. It was not necessary to reduce the cyclosporin $A$ dose because of high cyclosporin A blood concentrations.

\section{Discussion}

It has now been convincingly shown that cyclosporin A is highly effective in clearing

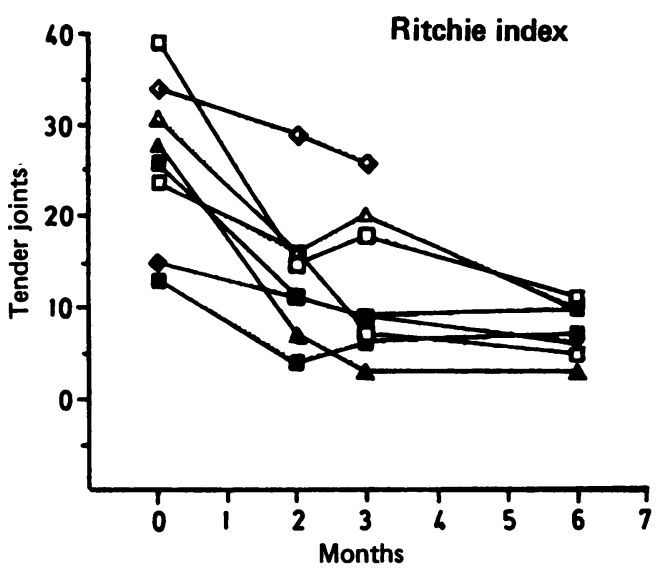

psoriatic skin lesions. ${ }^{568}$ As similar pathogenic mechanisms are likely to function in the skin and the joints of patients with psoriasis a test of the effect of this drug on patients with severe psoriatic arthritis not responding to conventional treatment seemed justified.

In this paper the first phase (six months) of an open study to determine the efficacy of cyclosporin $A$ in the treatment of psoriatic arthritis is reported. Seven of eight patients showed a marked improvement within two months with a dose of $3.5 \mathrm{mg} / \mathrm{kg}$ daily or less. To maintain the improvement the dose had subsequently to be increased to $5.0 \mathrm{mg} / \mathrm{kg}$ daily in one of the patients after four months. The remaining patients continued to improve with a dose of 3.5 $\mathrm{mg} / \mathrm{kg}$ daily or less. Subjective improvement was generally first noted within two weeks of treatment, often as reduced skin itching and decreased early morning joint stiffness. A progressive and sustained improvement was recorded throughout the study. After six months $55-80 \%$ improvement was recorded for the individual clinical variables.

In this study the side effects were similar to those reported by others ${ }^{11}$ and, in general, mild and reversible.

A decline in renal function dependent on dose has been noted in patients with rheumatoid arthritis receiving cyclosporin A treatment. ${ }^{12-14}$ Our study confirms that cyclosporin A treatment requires careful patient selection and close supervision.

The risk of interaction with nephrotoxic 
agents and the similarity between the nephrotoxic effects of non-steroidal anti-inflammatory agents and cyclosporin $\mathrm{A}$ has been pointed out. ${ }^{15}$

A higher incidence of increase in serum creatinine and hypertension has been reported in patients with rheumatoid arthritis receiving cyclosporin $A .^{12}$ This is probably due to a higher dose of cyclosporin A, concomitant use of nonsteroidal anti-inflammatory agents, and possibly also older patients. Therefore it may be important to encourage patients with arthritis to reduce their intake of non-steroidal drugs during treatment with cyclosporin $\mathbf{A}$.

The results of this study confirm the efficacy of cyclosporin A on skin manifestations of psoriasis and suggest that this drug may be equally effective for psoriatic arthritis. A close correlation was found between improvement in the indices for arthritis and improvement in skin, suggesting that similar pathogenic mechanisms are functioning in both sites.

Therefore we are currently working on phase 2 of this study, but the findings presented in this paper indicate that a randomised controlled trial of cyclosporin A for psoriatic arthritis is justified.

1 Baker B S, Swain A F, Fry L, Valdimarsson H. Epidermal T lymphocytes and Dermatol 1984; 110: 555-64.
3. Sackstein R, Falanga V, Streilein J W, Chin Y H. Lymphocyte adhesion to psoriatic dermal endothelium is mediated by a tissuc-specific receptor/ligand interaction. $\mathcal{f}$ Invest Dermatol 1988; 91: 423-8.

3 Placek W, Haftek $M$, Thivolet J. Sequence of changes in psoriatic epidermis. Archives of Dermatology and Venereolog 1988; 68: 369-77.

4 Valdimarsson H, Baker B S, Jónsdóttir I, Fry L. Psoriasis: a disease of abnormal keratinocyte proliferation induced by $\mathrm{T}$ lymphocytes. Immunology Today 1986; 7: 256-9.

5 Joost Th van, Heule F, Stolz E, Beukers R. Short-term use of cyclosporin A in severe psoriasis. Br $\mathcal{Y}$ Dermatol 1986; 114 cyclospori
$615-20$.

6 Griffiths C E M, Powles A V, Leonard J N, Fry L, Baker $B$ S, Valdimarsson $H$. Clearance of psoriasis with low dose cyclosporin. Br Med f 1986; 293: 731-2.

7 Ellis C N, Gorsulowsky D C, Hamilton T A, et al. Cyclosporin improves psoriasis in double-blind study. JAMA 1986; 256: 3110 .

8 Joost Th van, Bos J D, Heule F, Meinardi M M H M. Lowdose cyclosporin $A$ in severe psoriasis. A double blind study. Br $\mathcal{f}$ Dermatol 1988; 118: 183-90.

9 Cooperating clinics of the American Rheumatism Association. A seven-day variability study of 499 patients with peripheral A seven-day variability study of 499 patients with peripher

10 Ritchie D M, Boyle J A, McInnes J M, Grieveson P Buchanan W W . Clinical studies with an articular index for
, the assessment of joint tenderness in patients with rheumatoid arthritis. $Q \mathcal{F}$ Med 1968; 37: 393-406.

11 Palestine A G, Nussenblatt R B, Chan C-C. Side effects of systemic cyclosporin in patients not undergoing transplantation. Am ₹ Med 1984; 77: 652-6.

12 Weinblatt M E, Coblyn J S, Fraser P A, et al. Cyclosporin A treatment of refractory rheumatoid arthritis. Arthritis Rheum 1987; 30: 11-17.

13 Yocum D E, Klippel J H, Wilder R L, et al. Cyclosporin A in severe, treatment-refractory rheumatoid arthritis. Ann severe, treatment-refractory

14 Tugwell $P$, Bombardier $C$ Gent $M$, et al. Low dose cyclosporin in rheumatoid arthritis: a pilot study. f Rheumatol 1987; 14: 1108-14.

15 Keown P A, Stiller C R, Wallace A C. In: Williams G M, Burdicle J F, Solez K, eds. Nephrotoxicity of cyclosporine A. Kidney transplant rejection. New York: Marcel Dekker, 1986: 423. 